\title{
Recidiva Oncológica: Olhares dos Profissionais Hospitalares sobre as Dificuldades do Paciente Pediátrico
}

\author{
Susana Caires ${ }^{1}$ \\ Marta Machado ${ }^{1}$ \\ Maria Conceição Antunes' \\ Ana Sofia Marques Melo \\ ${ }^{1}$ Universidade do Minho, Braga, Portugal
}

\begin{abstract}
Resumo
Em pediatria oncológica, a taxa de sobrevivência tem sofrido um aumento acentuado, sendo considerável a probabilidade de cura. Não obstante, o processo de confronto com a doença pode sofrer alguns contratempos, nomeadamente uma recidiva. Esta última é responsável por elevado sofrimento, o qual poderá ser ainda maior que o confronto com o diagnóstico. Procurando conhecer as perceções dos profissionais de oncologia, relativamente às principais dificuldades experienciadas pelas crianças e adolescentes cuja doença recidivou, as autoras desenvolveram um estudo investigando o olhar desses profissionais. Entrevistaram-se 17 profissionais, de dois hospitais portugueses, exercendo funções hospitalares na área da saúde, serviço social, psicologia e educação. Suas reflexões apontaram como principais dificuldades a aceitação de ter que passar novamente por um processo fisica e psicologicamente penoso sendo que, entre os adolescentes - mais conscientes da gravidade da doença e suas implicações - acrescem as dificuldades em ter esperança na cura. Para os mais pequenos, os profissionais apontaram como mais comum a dificuldade em compreender os motivos de nova submissão a tratamentos dolorosos e do afastamento dos seus contextos de vida. Dando a conhecer uma etapa particularmente desafiante da doença oncológica, o presente estudo traz um olhar multifocal de um grupo de profissionais que acompanham de perto essas crianças/adolescentes (e respectivas famílas). A sua longa e diversa experiência - em termos de tipologias de câncer, evolução do quadro clínico, idade ou temperamento dos pacientes (e dos próprios pais) - fazem desses profissionais informantes-chave no mapeamento das dificuldades associadas ao processo de recidiva oncológica em pediatria, bem como no desenho e implementação de respostas mais ajustadas à fenomenologia destes processos.

Palavras-chave: psico-oncologia pediátrica, recidiva, fenomenologia, profissionais de cuidados
\end{abstract}

\section{Cancer recurrence: perspectives of hospital staff on} the difficulties of pediatric patients

\begin{abstract}
In pediatric oncology, the survival rate has risen considerably, and nowadays the probability of cure is very high. However, the process of fighting the disease can suffer some setbacks, namely a relapse. This event is responsible for high suffering, which may be even greater than dealing with the diagnosis of cancer. Aiming to understand the perceptions of oncology professionals regarding the main difficulties experienced by children/adolescents whose cancer relapsed, the authors developed a study in which the professionals' perspective was explored. A group of 17 professionals (from the areas of health, social work, psychology and education), working in two Portuguese hospitals, was interviewed. Their reflections indicated that the main difficulties during relapse were the acceptance of having to undergo such a - physically and psychologically - painful process all over again, and among adolescents, who are more aware of the severity of the disease and its implications, also difficulties in keeping up hope. Among the youngest, professional pointed out as more common the difficulty in understanding why they have to be resubmitted to such painful treatments and be parted from their life contexts. Emphasizing recurrence as a particularly challenging stage of the oncologic disease, this study brings a multifocal view of a group of professionals who closely follow these children/adolescents (and their families) all the way trough. Their long and diverse experience - in terms of type of cancer, evolution of the disease, age and/or temperament of the patients (and the parents' themselves) - make these professionals key informants in the mapping of the difficulties related to the pediatric oncological relapse, as well as in the design and implementation of more adjusted responses to the phenomenology of these processes.
\end{abstract}

Keywords: pediatric psycho-oncology; relapse, phenomenology; healthcare staff.

\section{Recaída oncológica: observación de los profesionales de hospitales} sobre las dificultades del paciente pediátrico

\section{Resumen}

En pediatría oncológica, el índice de sobrevivencia ha experimentado un aumento acentuado, siendo considerable la probabilidad de cura. Sin embargo, el proceso de enfrentar la enfermedad puede sufrir algunos contratiempos, en particular una recaída; ésta es responsable por mucho sufrimiento, el cual puede ser incluso mayor que enfrentar el propio diagnóstico. Tratando de conocer las percepciones de los profesionales de oncología y las principales dificultades experimentadas por los niños/adolescentes que tuvieron recaída, los autores desarrollaron un estudio con participación de 17 profesionales de la salud, trabajo social, psicología y educación de dos hospitales portugueses. Las reflexiones recogidas a través de entrevistas indicaron que las principales dificultades de los niños es aceptar y entender porqué razón tienen que pasar nuevamente por un proceso físico y 
psicológico tan doloroso y estar lejos de sus contextos naturales. Entre los adolescentes - más conscientes de la gravedad e implicaciones de la enfermedad - son mayores las dificultades para creer y tener esperanza en la cura. Describindo la recaída como una etapa particularmente difícil de la enfermedad oncológica, este estudio proporciona una mirada multifocal de un grupo de profesionales que siguen de cerca estos niños/adolescentes (y respectivas familias). Su larga y variada experiencia - en términos de tipos de cáncer, evolución de cuadro clínico, edad y temperamento de los pacientes (y de los propios padres) - hace que estos profesionales pasen a ser informantes clave para identificar las dificultades asociadas con la recaída del cáncer pediátrico, así como en el diseño e implementación de respuestas más ajustadas a la fenomenología de estos procesos.

Palabras-clave: psico-oncología pediátrica; recaída; fenomenología; profesionales de cuidados.

Em cada ano, mais de 200,000 crianças são diagnosticadas com câncer (World Health Organization, 2017) constando, atualmente, em grande parte dos países em desenvolvimento como a segunda causa de mortalidade infantil após o primeiro ano de vida. No entanto, a melhoria continuada do prognóstico nas últimas décadas permitiu que, mais recentemente, mais de $80 \%$ das crianças e adolescente diagnosticadas com câncer conseguem sobreviver à doença (WHO, 2017).

Apesar do cenário cada vez mais otimista, se tratando da cura da doença com maior estigma no Mundo Moderno (Pereira \& Lopes, 2002), é significativo o impacto físico e psicossocial do câncer em qualquer etapa do desenvolvimento humano. As dificuldades associadas à fenomenologia do câncer parecem ser tanto maiores e mais profundas quanto menor a idade do indivíduo e quanto mais prolongado o processo de doença e tratamentos. Assim, as evidências empíricas na área revelam que quando diagnosticado na infância ou na adolescência, o câncer afeta de forma particularmente acentuada o desenvolvimento e bem-estar desses pacientes (e suas famílias) dado que exige várias alterações no seu dia a dia e obriga a múltiplos esforços de adaptação à doença e ao seu tratamento prolongado (Lacaz, 2003; Valle, 2010). Em consequência, aumenta a vulnerabilidade física e psicossocial desses pacientes (e suas famílias), com repercurssões a médio e longo prazo (Araújo, 2011; Barros, 2003; Hinds, Birenbaum, Pedrosa, \& Pedrosa, 2002; Motta, 2007). A par do afastamento dos seus contextos naturais, o fato da criança ser forçada a conviver com um ambiente e com pessoas estranhas, de ser alvo de múltiplos procedimentos e tratamentos dolorosos e invasivos (que poderão revelar-se traumáticos), bem como estadias prolongadas no hospital (longe da família, amigos e escola) constituem motivos de vulnerabilidade acrescida (Araújo, 2011; Barros, 2003; Motta, 2007; Ciporah, Tadmor, Rosenkranz \& Weyl Ben-Arush, 2012).

Quanto aos fatores que determinam o impacto desses processos, a literatura na área (e.g., Barros, 2003;
Papalia, Olds, \& Feldman, 2009; Trianes, 2002) aponta a sua associação a aspetos de ordem desenvolvimental. Assim, numa fase mais precoce do seu desenvolvimento (período pré-escolar), a criança não consegue perceber o porquê dos tratamentos, nem a gravidade da doença, ficando assustada e confusa no confronto com eles. Tendencialmente, esta interpreta os acontecimentos associados à doença (afastamento da família e/ou a submissão a tratamentos e procedimentos dolorosos e invasivos) como um castigo, em consequência de ter feito ou desejado algo de mal. Efetivamente, segundo Zavaschi (1993), entre os quatro e os cinco anos - período que Piaget (1972) designa de "estádio pré-operatório" (início do pensamento simbólico, no qual a experiência concreta é substituída pelas ideias e a criança passa a dividir o mundo entre "o bom" e "O mau") - a culpa é um sentimento frequente, podendo a doença e tratamentos ser entendidos como uma consequência da sua conduta inadequada.

De acordo com Trianes (2002), entre os 5 e os 10 anos, a criança começa a ter uma visão do mundo mais objetiva e flexível, encontrando-se naquele que Piaget (1972) designa de «estádio das operações concretas». Neste, a sua nova conceção do mundo vai alterar a forma como encara a doença, tornando-se mais atenta, procurando informação e colocando questões relativas a ela e aos seus tratamentos. Revela, também, alguma preocupação acrescida com a privacidade, e verifica-se, entre algumas delas, excessiva obediência e passividade, reações que podem ocultar problemas de falta de confiança, ausência de competências e/ou parcas ou inadequadas estratégias de enfrentamento para lidar com o estresse gerado pela doença. No seu confronto com as dificuldades em compreender e tolerar o processo de doença e seus tratamentos, a criança entre os 5 e os 10 anos vai recolhendo pistas sobre o que se passa a partir da observação das reações dos seus cuidadores, apreendendo alguns "sinais" sobre a gravidade da situação. Pelo fato de tais sinais não serem explícitos e, consequentemente, a criança não os conseguir descodificar de forma linear (porque frequentemente 
"camuflados" pelos adultos, que procuram omitir-lhe o que se está pensando), a sensação de falta de controle pode assumir ainda maiores proporções e associar-se à já difícil gestão da perda de autonomia provocada pelas suas limitações físicas e pela necessária obediência às regras hospitalares.

Por volta dos 11 anos, a par das profundas mudanças ao nível do desenvolvimento físico e psicossocial desses indivíduos - e do ter que lidar com desafios e exigências nunca antes experimentados -, o confronto com a doença oncológica acarreta um conjunto de experiências adicionalmente críticas (Ettinger \& Heiney, 1993; Machado, 2014; Pimenta, 2013). Assim, para além das significativas alterações corporais de que são "palco"; dos processos de construção identitária; autonomização parental; maiores responsabilidades acadêmicas e sociais; e/ou do confronto com questões mais associadas à sexualidade e intimidade (Sprinthall \& Collins, 2003), os (pré) adolescentes com doença oncológica têm ainda que se confrontar com a ameaça de morte, e com todo o sofrimento (físico e psicológico) relacionado com a doença, seu tratamento e efeitos colaterais. Segundo Ettinger e Heiney (1993), estes experienciam um verdadeiro conflito ou, mesmo, incompatibilidade com as tarefas desenvolvimentais normativas da adolescência. A isto deve-se o fato das suas competências cognitivas já permitirem compreender a dimensão da ameaça que a doença representa, aspetos ainda não conscientes entre os pacientes mais jovens.

Assim, face ao comprometimento dos processos de autonomização em relação às figuras parentais; das alterações na sua imagem corporal (e.g. perda de cabelo, aumento de peso, amputação de membros); das inúmeras limitações que a doença, a hospitalização e os tratamentos acarretam (dores, restrições alimentares, perda de privacidade e liberdade); bem como, entre outros, da privação dos seus cenários de vida e do convívio com o seu grupo de pares, a doença oncológica expõe o (pré)adolescente a inúmeras situações de intenso e prolongado estresse (Abrams, Hazen, \& Penson, 2007; Machado, 2014). Nesse enquadramento, parece ser legítimo afirmar que "conviver" com o câncer na adolescência, é um processo particularmente exigente e complexo, constituindo-se num duplo desafio desenvolvimental que, à semelhança da doença oncológica na infância, poderá ter um enorme impacto nas suas vidas (e das suas famílias) no imediato e, a médio e longo prazo (Godinho, 2010; Machado, 2014; Vieira \& Lima, 2002).

\section{Recidiva Oncológica: Aspetos Fenomenológicos}

Apesar dos notáveis progressos científico-tecnológicos ocorridos nessa área nos últimos anos, nem sempre os tratamentos oncológicos surtem os efeitos esperados. Em alguns acasos, inclusive, apesar de algum do sucesso atingido, após um maior ou menor período de remissão, o câncer pode reaparecer (na mesma ou noutra parte do corpo), dando lugar a uma recidiva, a qual poderá ser experienciada mais do que uma vez ao longo de todo o curso da doença.

Quanto aos sentimentos e reações emocionais associadas ao confronto com a notícia da recidiva, assim como o impacto psicossocial que esta etapa da doença tem nas crianças e adolescentes, e seus familiares mais próximos, poucas são as evidências científicas existentes. Arruda-Colli e Santos (2015; p. 78), procurando dar resposta à questão "Qual é o status do conhecimento produzido sobre as vivências do paciente e seus cuidadores diante da recidiva em Oncologia Pediátrica?", encetaram uma revisão integrativa da literatura científica na área (publicada em português, espanhol ou inglês, até junho de 2015). Desse investimento resultou a constatação da escassez de investigações sobre a vivência da recidiva, em contraste com os investimentos feitos até à data ao nível do estudo do impacto psicossocial do diagnóstico de câncer e da fase terminal. Adicionalmente, os autores verificaram um maior volume de produção científica reportada às vivências dessa etapa por parte dos pacientes adultos. Tal produção, como afirmam os autores, muito embora dê contributos de relevo à compreensão das demandas e repercurssões psicossociais da recidiva oncológica, "o produzido com pacientes adultos não pode ser generalizado para a população infantil" (p. 78).

Em face desse cenário, Arruda-Colli e Santos (2015) - à semelhança de Hinds et al. (2002) -, enfatizam a necessidade de estudos que atendam às especificidades dessa etapa do tratamento oncológico durante a infância e a adolescência. Por meio do observado, poder-se-á fundamentar o desenho e implementação de intervenções que melhor se ajustem às necessidades psicossociais destas crianças e adolescentes durante a recidiva, e que melhor as munam, em termos de estratégias de coping, para fazer face aos desafios e exigências colocados pela recidiva da doença.

Numa tentativa de dar a conhecer o parco conhecimento existente nessa área, procede-se, em seguida, à síntese de alguns dos principais resultados de estudos 
que, mais recentemente, procuraram trazer alguma "luz" a esta temática. Entre esses consta o estudo desenvolvido por Araújo (2011), em Portugal, que descreve as reações associadas ao confronto com a notícia de uma recidiva como muito semelhantes às do diagnóstico de câncer. Segundo as evidências recolhidas por esta pesquisadora (e indo ao encontro do estudo de Vivar, Whyte, \& Mcqueen, 2010), o confronto com esta notícia é ainda mais difícil de ultrapassar uma vez que implica - para a criança/adolescente e sua família o reviver de todos os problemas anteriores, acrescidos de redobradas preocupações com o fato de as probabilidades de cura se verem diminuídas. Retratando as dificuldades inerentes a este confronto, Valle (2010, p. 139) descreve a recidiva como podendo ser:

"mais devastadora que o diagnóstico inicial, pois já se sabe o que terá de ser enfrentado. Os pais descrevem a primeira recidiva como o tempo mais difícil, principalmente quando já tinha ocorrido um aparente sucesso no tratamento. Eles sabem que a chance de cura diminui drasticamente. Esse momento caracteriza-se por tumulto, reavaliação, mudança e maior entropia familiar."

Vários autores salientam os riscos imediatos, ao nível psicossocial que, quer o paciente, quer a família encaram aquando da recidiva do câncer (e.g., ArrudaColli \& Santos, 2015; Hinds et al., 2002; Vivar, Canga, \& Arantzamendi, 2009). A sua confirmação é, entre outros, geradora de alterações ao nível das relações entre o paciente e os pais, e com a equipe prestadora de cuidados. Tais alterações são também visíveis na relação dos pais com a equipe de saúde, e com os pais de outros pacientes. Segundo Machado (2014) é, por vezes, mais difícil para a família aceitar toda a situação do que para o próprio paciente pediátrico. Ansiedade, depressão, medo da separação e/ou da perda do filho, estão habitualmente presentes entre estes pais (ArrudaColli, Lima, Perina \& Santos, 2016; Machado, 2014; Valle \& Mello, 1999); estados emocionais que poderão comprometer a qualidade do próprio apoio que prestam ao filho nessa fase da doença.

Quanto às consequências psicossociais da recidiva entre os próprios pacientes pediátricos, Koocher e O’Malley (1981) avaliaram 121 sobreviventes de câncer infantil, 22 dos quais tendo experienciado uma ou mais recidivas. No seu estudo pioneiro, exploraram (entre outros) as relações entre variáveis específicas e o tempo de adaptação à experiência de câncer na infância, tendo verificado que aqueles cuja doença recidivou apresentavam, habitualmente, mais dificuldades de ajustamento psicológico, designadamente depressão residual, ansiedade e/ou baixa autoestima.

Hockenberry, Dilorio e Kemp (1995), procurando averiguar quais as áreas mais afetadas pela duração dos tratamentos e da recidiva, estudaram 44 pacientes oncológicos. De entre estes, 15 tinham experienciado uma recidiva durante ou no fim do tratamento. $\mathrm{O}$ estudo revelou que pacientes que tinham experienciado uma recidiva e cujo tratamento se prolongou mais no tempo apresentavam uma autoestima global mais deficitária e traços de ansiedade mais pronunciados.

Adicionalmente, Arrais e T. Araújo (2000), num estudo com 10 crianças brasileiras sobreviventes de câncer (e respetivos pais) observaram - no quotidiano e nas "fantasias" destas crianças -, a presença de algumas preocupações com a saúde e o medo da recidiva. Entre os pais estas eram ainda mais marcadas. Refira-se, no entanto que, apesar das dificuldades observadas, os autores verificaram, também, entre estas crianças, a presença de crescentes níveis de otimismo e esperança relativamente à remissão definitiva do câncer, e níveis de adaptação aos seus diferentes contextos e tarefas desenvolvimentais bastante satisfatórios. Apesar de reportado a um grupo bastante restrito, os resultados são apontados pelos autores como permitindo uma visão mais otimista destes processos, ao contrário das evidências salientadas por estudos anteriores.

Procurando conhecer mais aprofundamente a fenomenologia destes processos entre pacientes portugueses, e num quadro cronológico mais recente, os autores desenvolveram um estudo cujo objetivo foi auscultar as perceções dos profissionais de oncologia pediátrica quanto às principais dificuldades vividas pelas crianças/adolescentes com doença oncológica durante a recidiva da doença. Tal opção prendeu-se, por um lado, com questões éticas (dado o caráter algo intrusivo do estudo, uma vez que centrado em experiências particularmente dolorosas) e, por outro, com questões associadas à riqueza, diversidade e longevidade da experiência dos profissionais de oncologia. Ou seja; julgou-se que a auscultação dos profissionais de oncologia, em alternativa aos pacientes oncológicos, permitiria, por um lado, evitar o confronto destes últimos com questões suscetíveis de algum sofrimento psicológico e, ao mesmo tempo, aceder a um reportório de experiências e conhecimentos particularmente rico e multifocal uma vez que provindo de profissionais de várias áreas de intervenção, com experiência de acompanhamento de diversos casos, cada qual com 
as suas particularidades (e communalidades), designadamente em termos de diagnóstico, evolução clínica, idades e/ou estratégias de coping adotadas no confronto com a recidiva.

\section{Método}

\section{Participantes}

O estudo contou com a participação de 17 profissionais das áreas de saúde, educação, serviço social e psicologia desempenhando funções em dois hospitais públicos portugueses. A seleção dos participantes fez-se por amostragem por conveniência e assumiu como critérios de inclusão (i) experiência profissional em oncologia pediátrica de pelo menos um ano; (ii) pertença ao grupo de profissionais que trabalham (nos serviços de internamento ou de ambulatório) em estreito contato com as crianças e adolescentes (e seus pais); (iii) disponibilidade para colaborar no estudo.

Na Tabela 1 dão-se a conhecer as principais características do grupo de participantes em termos da sua categoria profissional, anos de experiência em saúde e anos de serviço em pediatria oncológica.

Quanto ao contexto de trabalho, os 17 participantes desenvolvem a sua atividade profissional em dois hospitais do norte de Portugal, cada qual com um serviço de pediatria oncológica. A sua atividade profissional implica o contato com pacientes dos 0 aos 18 anos, designando-se o grupo 0-1 ano por grupo "dos bebés"; entre os 2 e os 5, anos a criança "pré-escolar"; entre os 5 e os 10 anos, a "criança em idade escolar"; os "pré-adolescentes" entre os 11 e os 13 anos; e, os "adolescentes" entre os 14 e os 18 anos. Quanto à sua categoria profissional, o estudo abarcou duas médicas (uma delas especializada em Oncologia Pediátrica e responsável pelo Ambulatório e pela equipe dos Cuidados Paliativos Pediátricos); sete enfermeiras (quatro especialistas); quatro profissionais de educação (duas professoras e duas educadoras de infância); um psicólogo, uma assistente social, e duas assistentes operacionais (i.e.; auxiliares de enfermagem).

Relativamente à idade, esta oscila entre os 30 anos e os 54 anos, situando-se a média nos 40,3 anos (sendo que dois participantes não divulgaram a sua idade). Quanto à longevidade da sua experiência na área da saúde, esta oscila entre os 4 e os 29 anos, com uma média de 15,3 anos. Relativamente ao seu tempo de serviço em Pediatria Oncológica, os valores situam-se entre 1 e 29 anos, com uma média de 10,1 anos.

Refira-se que, por forma a manter o anonimato dos participantes, foi atribuído um código a cada um deles (e.g., 16 E-I-I, 13 M-I-A).

\section{Instrumentos}

As perceções dos profissionais de oncologia pediátrica em torno das dificuldades experienciadas pelas crianças e adolescentes durante a recidiva foram recolhidas por meio de uma entrevista semiestruturada. Nesta, por intermédio da seguinte questão aberta "Quais as principais dificuldades que julga serem experienciadas pelas crianças e adolescentes aquando da recidiva da sua doença”, os participantes eram convidados a refletir sobre os diferentes casos que tiveram a oportunidade de acompanhar ao longo dos seus anos de experiência.

Tabela 1

Perfil Profissional dos Participantes

\begin{tabular}{lccccccc}
\hline \multirow{2}{*}{ Categoria profissional } & \multicolumn{4}{c}{ Anos de serviço na saúde } & \multicolumn{2}{c}{ Anos de serviço na oncologia } \\
\cline { 2 - 8 } & $\mathrm{M}$ & Min. & Máx. & M & Min. & Máx. \\
\hline Assistentes operacionais/auxiliares & 2 & 10 & 5 & 15 & 10 & 5 & 15 \\
Assistente social & 1 & & 14 & & & 8 & 21 \\
Educadores da infância & 3 & 17.7 & 8 & 24 & 16.7 & 5 & 9 \\
Enfermeiros & 6 & 16.5 & 9 & 28 & 16 & 9 & 12 \\
Médicos & 2 & 19 & 18 & 20 & 10.5 & 9 & 8 \\
Professores & 2 & 8 & 8 & 8 & 8 & 8 & 18 \\
Psicólogo & 1 & & 29 & & & & \\
\hline
\end{tabular}




\section{Procedimentos}

Numa fase inicial, o projeto de investigação foi submetido à apreciação das Comissões de Ética de dois hospitais que iriam acolher o estudo. Uma vez aprovado nos dois contextos (referência CES-IPO: 203/2013, a 9 e 24 de maio de 2013), avançou-se para a recolha das entrevistas. Estas ocorreram em local indicado por cada chefe de serviço, salvaguardando, sempre, condições de privacidade dos participantes e a não interrupção da entrevista. Antes de proceder à entrevista, apresentou-se, a cada um dos participantes, o enquadramento institucional e objetivos do estudo, seguindo-se a clarificação das questões éticas inerentes ao mesmo, designadamente o caráter voluntário da sua participação no estudo, a confidencialidade dos dados recolhidos, a salvaguarda da sua identidade, e a necessidade do seu consentimento informado para gravação áudio da entrevista e divulgação (anônima) dos resultados. Os dados foram recolhidos por três pesquisadores do projeto que integram o presente estudo, todos eles com treino e experiência prévia em condução de entrevistas. Cada entrevista durou aproximadamente 90 minutos.

\section{Tratamento dos Dados}

Após a realização das entrevistas, procedeu-se à sua transcrição integral, seguida da sua análise descritiva. Recorrendo à metodologia da análise de conteúdo assente na abordagem fenomenológico-hermenêutica proposta por Heidegger (1962), o processo de análise foi feito passo a passo, e envolveu uma descrição introdutória dos relatos dos participantes e as possíveis ligações entre eles. Os aspetos mais detalhados das reflexões destes profissionais constituíram o ponto de partida, os quais foram, posteriormente, integrados numa perspetiva mais profunda e holística, em resultado da síntese dos dados, num movimento dinâmico e circular entre a "parte" e o "todo" que Heidegger (1962) designa de "círculo hermenêutico" . Assumiu-se, pois, que "para compreender a parte há que olhar para o todo; para compreender o todo, há que olhar para a parte" (Smith, 2007, p. 5).

A análise realizada integrou: a) leitura compreensiva de cada um dos relatos; b) identificação das categorias temáticas inerentes aos relatos; c) interpretação das perceções dos profissionais de pediatria oncológica sobre as dificuldades das crianças/adolescentes em processo de recidiva.

Num primeiro momento, essa análise foi realizada por dois investigadores da equipe de pesquisa, tendo posteriormente sido remetida a um terceiro avaliador (coordenador do projeto) que procedeu ao acordo interavaliadores. Uma vez fechado o processo de análise qualitativa, procedeu-se à introdução dos dados numa base IBM-SPSS Statistics (versão 21) de modo a permitir a sua análise quantitativa.

\section{Resultados e Discussão}

Apresentam-se neste apartado as reflexões dos profissionais de oncologia sobre as principais dificuldades experienciadas pela criança/adolescente na recidiva. Refira-se que, em algumas das categorias de resposta (representadas em negrito), optou-se por não agregar a informação em categorias mais amplas, realçando a diversidade de respostas e a riqueza do seu conteúdo.

$\mathrm{Na}$ Tabela 2, dão-se a conhecer as diferentes categorias (e subcategorias) de dificuldades identificadas pelos participantes, bem como a frequência com que cada uma delas emerge no seu discurso. A sua apresentação (na tabela e no texto) aparece por ordem decrescente tendo em conta o critério "frequência". Assim, comentam-se em maior detalhe as dificuldades mais commumente referidas pelos profissionais entrevistados tendo também optado por, nalguns momentos, comentar as respostas menos frequentes, em particular aquelas cujo conteúdo se julgou merecer destaque uma vez que ilustram a diversidade e a intensidade das dificuldades experienciadas.

Tal como a Tabela 2 revela, são diversos os tipos de dificuldades inerentes ao confronto com a recidiva. De entre estas destaca-se a dificuldade das crianças/ adolescentes em "aceitar o fato de terem que viver tudo de novo," referida pela totalidade destes profissionais $(n=17)$. Segundo os seus testemunhos, as reações das crianças/adolescentes são ainda mais acentuadas do que aquando do confronto com a notícia de diagnóstico de câncer, à semelhança do que outros estudos vêm evidenciando (e.g., Araújo, 2011; Espíndula \& Valle, 2002; Machado, 2014). Essa maior intensidade decorre do fato de terem já conhecimento do que irá acontecer, de sentirem que os seus objetivos e expetativas foram defraudados, e que tudo regressou à “estaca zero". Nas palavras de um dos profissionais entrevistados:

"É o voltar a aceitar tudo aquilo que eles já conhecem. Por que, enquanto eles não conhecem, é um mundo de exploração que - se for bem acompanhado - é levado ao conforto. Quando já conhecem é muito complicado! Já sabem o que vai acontecer a seguir. Mesmo que seja tudo diferente, é um voltar ao passado...; mesmo que haja alguma distância 
Tabela 2

Dificuldades Crianças/Adolescentes na Recidiva Oncológica

\section{DIFICULDADES}

Em aceitar o fato de terem que passar por tudo de novo

Dificuldades emocionais $(n=9)$

Revolta/injustiça

Negação

Angústia

Depressão

Dificuldades em manter a esperança de cura

Dificuldades na gestão das restrições/condicionantes do internamento $(n=6)$

Isolamento

Tédio/"Marasmo"

"Enclausuramento"

Afastamento de casa

Dificuldade em lidar com os tratamentos

Dificuldade em abdicar da normalidade readquirida durante o período de remissão da doença 3

Dificuldade em manter o apoio familiar mais alargado

Dificuldade em lidar com a morte de outros companheiros

Dificuldade em gerir a vida escolar

Dificuldade em falar abertamente da recidiva com os seus pais

em termos de tempo, esse tempo, de repente, faz-se perto. E aquilo é como se fosse um filme que estão a ver ali à frente deles (...) é o reviver tudo; é como se estivesse lá bem guardadinho e, de repente, aquilo vem tudo [ao de cima], é como uma panela de pressão...É terrivel! É terrivel! (...) enquanto é novidade é difícil, mas, vão gerindo. Depois da novidade é abraçar o mundo naquilo que é possivel e impossivel..." (profissional 9-E-I).

O segundo tipo de dificuldades mais frequente corresponde às de foro emocional $(n=9)$, observandose, a esse nível, diferenças significativas nas dificuldades percecionadas entre os adolescentes e as crianças mais pequenas (mais acentuadas entre os primeiros). Conforme o olhar destes profissionais, a consciência/ maturidade dos adolescentes "mostra-lhes" o quão grave pode ser uma recidiva; daí reagirem muito mal à notícia, entrando alguns, numa fase inicial, em processo de negação. Nesta fase, os adolescentes são confrontados com uma mescla de sentimentos que vão desde a revolta, passando pela angústia, o sentimento de injustiça, até à depressão, tal como também Webster e Skeen (2012) referem reportando-se aos escassos estudos existentes na área. Estes sentimentos decorrem do fato de terem que passar por tudo de novo, sabendo, de antemão, as implicações que daí podem advir (Ettinger \& Heiney, 1993; Godinho, 2010; Vieira \& Lima, 2002) bem como da sensação de que a vida lhes foi novamente "roubada", tal como ilustram, os seguintes relatos:

\section{"(...) eles, nestas circunstâncias, ficam completamente "encurralados", porque, para o adolescente, aquilo que ele já viveu não presta para nada, não the dá consolo como realiza- ção pessoal; o presente é-lhe completamente roubado: ou está isolado, ou está em tratamento, ou tem que estar em casa" (profissional 13 M-I-A). \\ "Todos os sentimentos que isso traz consigo: a revolta; o passar por tudo isso outra vez; angústia; negação (...) a injustiça..." (profissional 3-E-I).}

Por seu lado, entre as crianças mais pequenas - e à semelhança do que Trianes (2002) e Araújo (2011) também referem -, as dificuldades experienciadas parecem traduzir-se, essencialmente, ao nível da presença de sentimentos de confusão, acima de tudo explicados pelo fato de não perceberem por que razão são submetidas a tratamentos dolorosos, ou porque são afastadas 
dos seus meios naturais de vida. Nalguns casos, entre os mais pequenos, o arrastar deste processo é frequentemente interpretado como um castigo por algo que fizeram de mal (Papalia et al., 2009; Trianes, 2002).

Em terceiro lugar surgem as dificuldades relativas à manutenção da esperança $(n=8)$, as quais parecem de algum modo associar-se às dificuldades anteriores. Sendo a recidiva encarada como o fracasso das anteriores tentativas de cura, o "recuo" ocorrido poderá ser particularmente desmoralizante, conduzindo à edificação de representações menos otimistas quanto à possibilidade de sucesso. Na mesma linha, Webster e Skeen (2012) fazem alusão à presença de sintomas depressivos entre os adolescentes afetados pela recidiva, assim como a perda de esperança na cura, e ansiedade em torno de um futuro incerto e da sua potencial morte. Nessas circunstâncias, o desânimo ganha, pois, terreno face à esperança, tal como ilustra o testemunho seguinte:

"As recidivas são muito complicadas. Toda a gente dir que é pior do que na fase do diagnóstico porque a "luzinha ao fundo do túnel" começa a ficar mais e mais pequenina... e o túnel mais comprido e sem certeza de que se chega lá. Portanto, é mais complicado..." (profissional 13 M-I-A).

Associadas a esse quadro surgem, também, dificuldades relativas às restrições e condicionamentos colocados pela doença, hospitalizações e tratamentos $(n=6)$. Tais restrições exigem cuidados que muitas vezes são difíceis de compreender e aceitar por parte da criança/adolescente, designadamente o afastamento do seu meio natural de vida (entre eles a casa, família, escola, amigos). No caso das crianças mais pequenas, afastadas do seu mundo familiar e devolvidas às rotinas do hospital e dos tratamentos, esta são, segundo Masetti (2011; p. 2), uma vez mais "destituídas da sua função: ser criança". Quanto aos mais velhos, a par da perda do seu "espaço" e privacidade, o afastamento do grupo de pares poderá ser também vivido de forma particularmente difícil (Abrams et al., 2007; Machado, 2015; Pimenta, 2013). Em suma: tudo o que é significativo para a criança ou para o jovem fica para lá das paredes do hospital, acrescido do fato de que, neste contexto, tem que permanecer, muitas vezes, em isolamento, sem poder sair, receber visitas, e sem grandes alternativas de entretenimento. Segundo alguns dos profissionais que enfatizaram estas dificuldades, as crianças/adolescentes sentem-se, por um lado, presos a um espaço e a uma doença que não os deixa continuar a viver as suas vidas e, por outro, com ofertas de entretenimento muito limitadas no contexto hospitalar. Os exemplos que seguidamente se transcrevem espelham essas restrições:

“(...) às vezes o que se constata é que nem sempre nós também temos meios que cheguem a eles, por exemplo: uma televisão ... estão cingidos a 4 canais, não têm TV Cabo. São 24 horas sobre 24 horas num espaço muito, muito pequeno... embora cada vez mais se tem visto que há um computador portátil, a net, mas nem sempre todos os têm. Também é um entrave”; “(...) Depois é o fator de não poder sair, de poder tomar ar (...)"(profissional 16 E-I-I);

"(...) Continuar com a vida deles, que é o problema do isolamento" (profissional 13 M-I-A).

Um menor número de profissionais $(n=4)$ enunciou dificuldades associadas ao confronto com os tratamentos. Tais dificuldades parecem verificar-se, quer ao nível físico (dor e desconforto experienciados), quer ao nível mais operacional, no manuseamento de alguma da parafrenália tecnológica que a aplicação dos tratamentos acarreta.

Para agravar esse cenário, nalguns casos, todas essas dificuldades ocorrem num período muito curto, sem que tenha existido tempo para, sequer, recuperar das fases anteriores. Eis um exemplo:

“(...) às veżes este período é tão curto; eles acabaram de
estar em remissão e estão ali um mês ou dois ou três e, de
repente, (...) aquilo ainda não tinha trabalhado, não houve
tempo e já estão a levar com outra e aí sem tempo de recupera-
cão. Ainda que ninguém esteja preparado para esta segunda
notícia (...) estão muito próximos do percurso, do primeiro
percurso. Aquilo ainda está tudo muito contaminado pela
primeira experiência; ainda estavam a começar a vigilância
ejá lhes aconteceu outra vez...” (profissional 30 P-I-A).

Para além do mais, o fato de ser uma doença que exige um período de tempo considerável de tratamentos e de inúmeras idas ao hospital para tratamento e análises cria, na criança/adolescente, a ideia que esta nunca desaparecerá da sua vida, evidenciando-se uma dificuldade em lidar com o seu caráter crónico. Adicionalmente, três dos profissionais entrevistados salientaram a dificuldade em abdicar da "normalidade" readquirida (em etapas intermédias do processo). Esta parece ainda mais acentuada nos casos em que as recidivas ocorrem após longos períodos de remissão, quando todos os indícios levavam a acreditar que a pior fase do processo já tinha sido ultrapassada, dando gradualmente lugar ao resgate da sua vida "normal" 
(escola, amigos, vida social...). Como sugere o testemunho que se segue:

\begin{abstract}
"Também é diferente uma recaida passado dois anos, quatro anos... Por um lado, toda a normalidade já tinha sido readquirida e, portanto, às vezes é difícil, mas, já houve um periodo livre de doença, já houve algum tempo de recuperação, até emocional e psicológica, mas... Muitas vezes essa recidiva aparece passado mais meio ano, um ano; muitas vezes já começaram a ter uma vida normal, em que já começaram a ir à escola, já comecaram a ter os amigos, já têm uma vida social ativa e vão deixar de tê-la outra vez, o que é muito complicado; é voltar a "arrancar-lhes" tudo a que eles tinham direito" (profissional 27 E-A).
\end{abstract}

Esses testemunhos vão ao encontro do que também é referido por Webster e Skeen (2012) na sua revisão da literatura, apontando reações emocionais mais expressivas (entre elas a depressão e a ansiedade) entre os adolescentes que se confrontam com a recidiva já depois de um longo período em que estiveram «livres» da doença.

Adicionalmente, nesse período de recidiva, a manutenção do apoio da família mais alargada pode também ser percebida como uma dificuldade entre as crianças/adolescentes, dado que o apoio prestado em etapas anteriores nem sempre se mantém, por circunstâncias várias, tal como evidencia o testemunho de um dos profissionais:

“(...) nem a familia olha com os mesmos olhos e, muitas vezes, a família que apoiou da primeira vez já não apoia da segunda vez; já não estão disponiveis: mudaram de emprego, a situação já é outra; já não olham da mesma forma" (profissional 17 E-I-I).

A perda de outros companheiros é também referida por dois profissionais como vivida com intensa dificuldade, à semelhança das descrições de Webster e Skeen (2012). Enquanto internadas, estas crianças/ adolescentes conhecem outros pacientes pediátricos com quem se vão relacionando e criando amizades. Quando um deles morre, os dias seguintes são particularmente difíceis, tal como descreve um dos profissionais:

“(...)... aqueles primeiros dias, para eles, é terrivel. Se eles sabem que um amigo partiu então, para eles é terrivel, mesmo" (profissional 20 AO-I).

Um dos profissionais salientou, ainda, a dificuldade na gestão da vida escolar aquando da recidiva, uma vez que esta provoca novo afastamento da escola, contexto onde estão os amigos, e a sua vida social e escolar. Segundo os dados empíricos sintetizados por Ciporah et al. (2012) em torno da relevância do contexto escolar para a saúde mental destas crianças, o apoio dos pares (mais do que o dos professores e, por vezes, dos próprios pais) e o manter a frequência da escola atuam como fatores protetores, atenuando as sequelas emocionais destes processos (e.g., menos sintomas depressivos, menores níveis de ansiedade, e ansiedade social, níves de autoestima mais elevados). A esse propósito, Klopovich et al. (1982), aludem a uma série de contributos que a frequência da escola representa para o bem-estar destas crianças/adolescentes, designadamente a promoção do contato social com pares da mesma idade; o aumento da moral/ânimo; a manutenção da dignidade; e, o conferir de alguma normalidade à sua vida. A estes Ciporah et al. (2012) acrescentam o fato de a continuidade da frequência da escola permitir que a criança se foque na dimensão saudável da sua vida, promovendo a esperança, e dando espaço para que se façam planos para o futuro.

Por fim, um dos profissionais entrevistados referiu a dificuldade destas crianças/adolescentes em falarem abertamente com os pais sobre a sua recidiva. Estas parecem decorrer do fato de alguns destes pais negarem a sua ocorrência ou de se recusarem a falar sobre a mesma com o filho. Eis o seu testemunho:

\section{"A maior parte dos pais prefere não falar ou fazer de conta "Não, não vai acontecer nada", o que, para a criança, não é muito bom. Ela arranja outra pessoa [para falar]... normalmente arranjam alguém que não está tão envolvida emocionalmente" (profissional 13 M-I-A).}

Ao evitamento, por parte dos pais, em falar abertamente sobre estas questões associa-se, por um lado, o fato de ser um processo muito doloroso para si próprios (envolvendo grande sofrimento e sentimentos de impotência) e, por outro, a sua tentativa de "poupar" o filho de sofrimento acrescido, o qual, segundo as suas crenças, fará perigar ainda mais o seu já frágil equilíbrio físico e psicológico e/ou levá-los a desistir de combater a doença (Machado, 2014; Webster \& Skeen, 2012). Assim, muito embora nas duas últimas décadas se tenham gradualmente vindo a verificar mudanças nas práticas médicas, no sentido de se promover uma comunicação aberta e honesta com a criança e o adolescente sobre a doença, a verdade é que muitos pais continuam a temer fazê-lo. Inclusive, alguns deles, bloqueiam ativamente esta discussão. Quanto aos efeitos 
colateriais do silêncio gerado em torno destas questões, as evidências mostram que, em face deste cenário, e à semelhança que os dados do presente estudo também revelam, as crianças/adolescentes tornam-se incapazes de comunicar sobre a sua situação com a família ou com o pessoal hospitalar bem como sobre os seus medos (Chesler, Paris, \& Barbarin, 1986), acabando por recorrer a outras fontes (e.g. amigos, internet...).

\section{Considerações Finais}

O trabalho aqui apresentado dá a conhecer o olhar de um grupo de profissionais de oncologia pediátrica em torno daquelas que lhes parecem ser as principais dificuldades experienciadas por crianças/adolescentes aquando do confronto com a recidiva do câncer. As reflexões destes profissionais em torno da fenomenologia desta etapa crítica do processo de tratamento dão a conhecer o amplo impacto psicossocial da recidiva oncológica entre as crianças e adolescentes que a protagonizam. Os seus testemunhos - fundamentados em experiências de vários anos acompanhando crianças e adolescentes com diferentes tipos de cancro, com diversos perfis sócio-demográficos e integrados em famílias com formas distintas de lidar com a doença e sua recidiva - tornam cada vez mais evidente que, em oncologia pediátrica (bem como noutras áreas da saúde/doença), o processo do cuidar e curar não deve centrar-se exclusivamente na doença ou na situação clínica de que a criança/adolescente é portadora. Deve, sim, tomar a pessoa integral e holística, e ir para além do corpo doente (Masetti, 2011; Parcianello \& Felin, 2008; Young, 1993).

Como evidenciaram os principais resultados deste estudo, as dificuldades experienciadas e vividas pelas crianças e adolescentes em recidiva oncológica não se situam unicamente na dimensão biofisiológica da dor face aos tratamentos mas, também, e fundamentalmente, ao nível psicológico, emocional e social resultado de um conjunto complexo de emoções e sentimentos negativos e de difícil gestão. Não obstante o fato de ter sido referenciada, contrariamente aquilo que poderíamos esperar, a maior dificuldade (dado ter sido referida pela totalidade dos profissionais) não recaiu na dimensão mais ou menos objetiva e comensurável da dor física face aos tratamentos, mas, sim, na dimensão psicológica subjetiva e incomensurável da "aceitação da ideia de ter que passar por todo o processo novamente". As dificuldades de caráter emocional revelaram-se, também, muito significativas, dado serem referidas frequentemente, evidenciando as dificuldades de lidar com emoções muito negativas como revolta; injustiça; angústia; depressão e desesperança.

As dificuldades ao nível do bem-estar subjetivo evidenciaram-se, ainda, no campo da relação com o outro, quer no que concerne às expectativas de apoio e suporte (por parte dos familiares e amigos), quer no que respeita às perdas (dos companheiros). Os resultados do presente estudo parecem indicar que as dificuldades das crianças/ adolescentes em recidiva oncológica vão muito além das dificuldades relacionadas com os procedimentos técnicos e medicamentosos a que são submetidos com vista ao re(equilíbrio) orgânico e biológico. Até mesmo porque este re(equilíbrio) para além desses procedimentos pressupõe outros componentes que se expressam no dado biológico (corpo) tais como o pensamento, a inteligência, as emoções, os afetos e a espiritualidade. Indo ao encontro da literatura referenciada (e.g., Young, 1993, Parcianello \& Felin, 2008; Masetti, 2011) os resultados corroboram a necessidade de uma perspetiva integral e holística do cuidar e curar a pessoa para além do seu corpo doente.

Para que estas respostas possam ser mais amplas e sustentadas, é de maior premência um investimento da pesquisa científica ao nível da identificação e conhecimento mais direto e aprofundado das experiências, dificuldades e desafios vivenciados pelo paciente pediátrico durante esta etapa. No presente estudo, a exploração destas vivências fez-se meramente por meio dos seus cuidadores formais (profissionais da área de saúde, psicologia, educação ou serviço social), dando "vOz" às experiências acumuladas ao longo da sua prática profissional. Apesar da relevância, amplitude e riqueza do seu olhar sobre estes fenónemos (uma vez que tendo acompanhando de perto, e por longos períodos de tempo, inúmeras crianças e adolescentes, com diferentes tipos de câncer, diferentes perfis sóciodemográficos e variados estilos de coping), ainda assim este é um olhar indireto, muito restrito (tendo em conta o tamanho da amostra) e incompleto (dado refletir apenas o olhar dos profissionais) daquelas que são as vivências nucleares destes processos. Assim, futuros estudos nesta área devem auscultar de modo direto o repertório experiencial destas crianças e adolescentes durante a recidiva e triangulá-lo com o olhar dos seus cuidadores formais e informais, em particular o dos profissionais e o dos seus pais. Tais investimentos podem favorecer o desenho e implementação de intervenções psicológicas mais eficazes ao nível da ressignificação destes processos e do apetrechar dos seus diferentes 
atores com estratégias de enfrentamento mais ajustadas (e concertadas entre si) aos múltiplos desafios que a doença oncológica e, em particular, a recidiva contêm.

\section{Referências}

Abrams, A. N., Hazen, E. P., \& Penson, R. T. (2007). Psychosocial issues in adolescents with cancer. Cancer Treatment Review, 33(7), 622-630. doi: 10.1016/j. ctrv.2006.12.006.

Araújo, M. (2011). A doença oncológica na criança: Adaptação e bem-estar psicológico das mães dos seus filhos e a relação entre ambos. Lisboa: Coisas de Ler.

Arrais, A. R., \& Araújo, T. (2000). Recidiva X Cura: A vivência paradoxal da sobrevivência ao câncer na infância. Revista Brasileira de Cancerologia, 46(3), 9-19. Recuperado de https://www.researchgate. net/publication/268417364_Recidiva_X_cura_a_ vivencia_paradoxal_da_sobrevivencia_ao_cancer_na_infancia_1_Relapse_X_Cure_the_paradox_of_surviving_cancer_on_childhood

Arruda-Colli, M. N. F., \& Santos, M. A. (2016). Aspectos psicológicos da recidiva em Oncologia Pediátrica: uma revisão integrativa. Arquivos Brasileiros de Psicologia, 67(3), 75-93.

Arruda-Colli, M. N. F., Lima, R. A., G., Perina, E. M., \& Santos, M. A. (2016). A recidiva do câncer pediátrico: Um estudo sobre a experiência materna. Psicologia USP, 27(2), 307-314. doi: 10.1590/0103-656420140078.

Barros, L. (2003). Psicologia pediátrica: Perspectiva desenvolvimentalista ( $2^{\mathrm{a}}$ ed). Lisboa: Climepsi Editores.

Caires, S., Esteves, C. H., Correia, S., \& Almeida, I. (2014). Palhaços de hospital como estratégia de amenização da experiência de hospitalização infantil. Psico-USF, 19(3), 377-389. doi: 10.1590/1413-82712014019003001

Chesler M. A., Paris J., Barbarin O. A. (1986). “Telling” the child with cancer: parental choices to share information with ill children. Journal of Pediatric Psychology, 11, 497-516. doi: 10.1093/jpepsy/11.4.497

Espíndula, A., \& Valle, M. (2002). Experiência materna diante da iminência de morte do filho com recidiva de câncer. Pediatria moderna, 38(5),188-199. Recuperado de http://www.moreirajr.com.br/revistas. asp?fase $=$ r003\&id_materia $=1916$
Ettinger, R., \& Heiney, S. (1993). Cancer in Adolescents and young adults: Psychosocial concerns, copig strategies, and interventions. Cancer, 71(10), 3276-3280. Recuperado em http: / / onlinelibrary.wiley.com/doi/10.1002/ 1097-0142(19930515)71:10\%2B\%3C3276::AID-CNCR2820711722\%3E3.0.CO;2-D/ pdf

Godinho, F. (2010). Efeitos a médio/longo prazo da doença oncológica na infância e adolescência (Tese de mestrado em Medicina). Porto: Faculdade de Medicina do Porto.

Heidegger, M. (1962). Being and time. Oxford: Blackwell.

Ciporah S.,Tadmor, R., Weyl Ben-Arush, M. (2012). Education in pediatric oncology: Learning and reintegration into school. Em S. Kreitler, M. W. Bem-Arush \& A. Martin (Eds.), Pediatric psycho-oncology: Psychosocial aspects and clinical interventions. (2nd edition, pp. 104-116). West Sussex, UK: John Wiley \& Sons.

Hockenberry, M., Dilorio C., \& Kemp, V. (1995). The relationship of illness longevity and relapse with self-perception, cancer stressors, anxiety, and coping strategies in children with cancer. Journal of Pediatric Oncology Nursing, 12(2),71-79.

Hinds, P. S., Birenbaum, L. K., Pedrosa, A. M., \& Pedrosa, F. (2002). Guidelines for the recurrence of pediatric cancer. Seminars in Oncology Nursing, 18(1), 50-59. doi: 10.1053/sonu.2002.30045

Lacaz, C. P. (2003). Descortinando o universo: A família da criança com câncer. São Paulo: Cabral.

Koocher, G. P., \& O’Malley, J. E. (Eds.). (1981). The Damocles Syndrome: Psychological consequences of surviving childhood cancer. New York: McGraw-Hill.

Machado, M. J. P. (2014). Vivência familiar da recidiva oncológica: A perspetiva dos profissionais de pediatria (Dissertação de mestrado não publicada). Insitituto da Educação da Universidade do Minho, Braga, Portugal.

Masetti, M. (2011). Ética da alegria. São Paulo: Sinergias.

Motta, A. B. (2007). Brincando no hospital: Uma proposta de intervenção psicológica para crianças hospitalizadas com câncer (Tese de doutoramento não publicada). Vitória: Universidade Federal do Espírito Santo. 
Papalia, D. E., Olds, S. W., \& Feldman, R. D. (2009). Human development (11th ed). New York: McGraw-Hill.

Pinto, A. (2016). Causas do cancro na criança.Trabalho apresentado no $2^{\circ}$ seminário de Pediatria Oncológica da Fundação Rui Osório de Castro, Lisboa, Portugal.

Pimenta, R. J. V. (2013). Cuidados Paliativos em Oncologia Pediátrica: Necessidades, preocupações e dificuldades dos pais e crianças/adolescentes na ótica dos profissionais (Dissertação de mestrado). Universidade do Minho, Braga.

Webster, M. L., \& Skeen, J. E. (2012). Communicating with children: Their understanding, information needs, and processes. Em S. Kreitler, M. W. BemArush \& A. Martin (Eds.), Pediatric psycho-oncology: Psychosocial aspects and clinical interventions (2nd edition, pp. 71-91). West Sussex, UK: John Wiley $\&$ Sons.

Parcianello, A. T., \& Felin, R. B. (2008). E agora doutor, onde vou brincar? Considerações sobre a hospitalização infantil. Barbarói, 28, 147-166. Recuperado de http://online.unisc.br/seer/index.php/barbaroi/ article/view/356/584

Pereira, M. G., \& Lopes C. (2002). O doente oncológico e a sua familia. Lisboa: Climepsi Editores.

Piaget, J. (1972). Os estágios do desenvohimento intelectual da crianca e do adolescente. Rio de Janeiro: Forense.

Smith, J. (2007). Hermeneutics, human sciences and health: Linking theory and practice. International Journal of Qualitative Studies on Health and Well-being, 2, 3-11. doi: 10.1080/17482620601016120

Sprinthall, N. A., \& Collins, A. W. (2003). Psicologia do adolescente. Lisboa: Fundação Calouste Gulbenkian.
Trianes, M. V. (2002). O stress na infância: Prevenção e tratamento. Lisboa: Edições Asa.

Valle, E. R. M. (2010). Psico-oncologia pediátrica (2a edição). São Paulo: Casa do Psicólogo.

Valle, E. R. M., \& Mello, L. L. (1999). Equipe de enfermagem, criança com câncer e sua família: Uma relação possível. Pediatria Moderna, 35(12), 970-972.

Vieira, M. A., \& Lima, R. A. G. (2002). Crianças e adolescentes com doença crónica: Convivendo com a mudança. Revista latino-americana de enfermagem, 10(4), 552-560. doi: 10.1590/S0104-11692002000400013

Vivar, C. G., Canga, N., Canga, A., \& Arantzamendi, M. (2009). The psychosocial impact of recurrence on cancer survivors and family members: A narrative review. Journal of Advanced Nursing, 65(4), 724-736. doi: 10.1111/j.1365-2648.2008.04939.

Vivar, C. G., Whyte, D. A., \& Mcqueen, A.(2010). Again': The impact of recurrence on survivors of cancer and family members. Journal of Clinical Nursing, 19(13-14), 2048-56. doi: 10.1111/j.1365-2702.2009.03145

Zavaschi, M. L. S. (1993). A reação da criança e do adolescente à doença e à morte. Revista de Bioética, 1(2), $165-172$.

Young, K. (1993). Narrative embodiments: Enclaves of the self in the realm of medicine. Em J. Shooter \& K. J. Gergen (Eds.), Texts of identity, pp.152-175. London: Sage publications.

World Health Organization (2017). Recuperado de http://www.who.int/cancer/en/

Recebido em: 26/04/2016

Reformulado em: 12/04/2017

Aprovado em: 21/07/2017 
Sobre as autoras:

Susana Caires é doutorada em Psicologia, especialista em Psicologia da Educação, investigadora do Centro de Investigação em Educação da Universidade do Minho (UM), docente do departamento de Psicologia da Educação e Educação Especial da UM e orientadora científica de teses de mestrado e doutoramento no âmbito da doença e hospitalização pediátrica.

E-mail: s.caires@sapo.pt

Marta Machado é mestre em Estudos da Criança, com dissertação de mestrado sobre a recidiva em oncologia pediátrica, pós-graduada em Gestão de Instituições Sociais e diretora técnica de uma Instituição Particular de Solidariedade Social.

E-mail:martajmachado@hotmail.com

Maria Conceição Antunes é doutorada em Educação, especialista em Filosofia da Educação, docente do Departamento de Teoria da Educação, Educação Artística e Física da Universidade do Minho (UM) e investigadora do Centro de Investigação em Educação (UM), na área da Educação ao Longo da Vida, Educação de Adultos e Intervenção Comunitária, e Educação/promoção da Saúde.

E-mail:mantunes@ie.uminho.pt

Ana Sofia Marques Melo é mestre em Psicologia, doutorando em Ciências da Educação, especialista em Psicologia da Educação em torno da oncologia pediátrica e investigadora do Centro de Investigação em Educação - Universidade do Minho. Possui ainda experiência profissional em meio clínico, educativo e escolar com crianças/adolescentes, pais e professores.

E-mail: anasofiamelo@hotmail.com

Contato com as autoras:

Susana Caires

Instituto de Educação da Universidade do Minho, Campus de Gualtar

4710-057

Braga, Portugal. 